\title{
FORMAÇÃO DE VALORES ATRAVÉS DOS JOGOS COOPERATIVOS COMO RECURSO PEDAGÓGICO.
}

\author{
Cristiane Maria Zambelli, Joyce Cristina Claro Menoti, José Milton de Lima
}

Departamento de Educação Física, Faculdade de Ciências e Tecnologia. UNESP - Presidente Prudente. Coordenação de Aperfeiçoamento de Pessoal de Nível Superior (CAPES), Programa Institucional de Bolsa de Iniciação à Docência (PIBID). E-mail: joyce_cris_1012@hotmail.com.

\section{RESUMO}

A pesquisa tem como objetivo estimular por meio dos jogos cooperativos a formação dos valores cooperação, perseverança e solidariedade. Será desenvolvida com alunos dos anos iniciais do Ensino Fundamental por meio da consideração do jogo cooperativo como recurso pedagógico na busca da apropriação por parte da criança, dos valores supracitados. O referencial teórico respalda-se em autores da Teoria Histórico Cultural, Cultura Corporal de Movimento e autores que discutem jogos cooperativos. A metodologia, de predominância qualitativa, caracteriza-se como pesquisa-intervenção, com medidas quali-quantativas. Os instrumentos se consubstanciam em registros escritos, fotografias, vídeos e questionários. Os resultados parciais obtidos até o momento demonstram que é de suma importância introduzir os jogos cooperativos como recurso pedagógico, pois, é uma atividade que proporciona, ajuda mútua entre os pares, o trabalho em equipe na busca de superar desafios em comum, e a interação com o próximo.

Palavras-chave: Educação Física, Jogos, Cooperação, Formação e Valores.

\section{INTRODUÇÃO}

A presente pesquisa pretende, por meio do jogo cooperativo, propiciar mudanças qualitativas nas atitudes dos alunos dos anos iniciais do Ensino Fundamental, de forma a oportunizar vivências que venham ao encontro da apropriação dos valores cooperação, perseverança e solidariedade.

A problemática da pesquisa surgiu a partir de intervenções de um subprojeto do Programa Institucional de Bolsas de Iniciação à Docência (PIBID) do curso de Licenciatura em Educação Física, em uma Unidade Escolar do município de Presidente Prudente, na qual se constatou que os alunos que participam do subprojeto têm dificuldades em cooperar durante as aulas, resultando em atitudes comportamentais negativas. Por isso, a necessidade da apropriação de alguns valores, de que se faz exemplo a cooperação, atualmente é desconsiderada no contexto escolar e secundarizada pela sociedade atual.

E neste contexto julgamos necessário proporcionar vivências que remetam aos valores objetivados, sendo assim, elaboramos um repertório de atividades no qual consta um variado rol de jogos cooperativos, jogos de regras, estafetas e demais atividades de caráter lúdico. Ao considerar-se que o jogo cooperativo pode possibilitar a interação entre pares por meio da 
comunicação, da recreação e da vivência de regras, conclui-se que o desenvolvimento dos aspectos cognitivo, afetivo, motor, social, ético e estético do aluno, venham a reboque.

Definimos o jogo cooperativo como aquele que desenvolve a capacidade em trabalhar em grupo na superação de desafios comuns em parceria, com o objetivo de alcançar o respeito mútuo, a compreensão dos pontos de vista diferentes, a alternação de experiências culturais vividas em seu cotidiano e a motivação da criança em participar de jogos coletivos, pois quando a criança é motivada no jogo ela se sente sujeito do processo.

Enquanto categorias de análises adotamos alguns valores que em nosso entender ocupam fundamental importância no processo de humanização do aluno, em destaque:

- Cooperação: define-se como a capacidade do sujeito de operar juntamente com outro, contribuindo com o cumprimento das combinações e, respeitando diferentes pontos de vista em atividades que requeiram a complementaridade de ações, ou seja, necessita da colaboração intencional entre todos os membros do grupo para a contemplação de metas em comuns.

- Perseverança: Caracteriza-se pela persistência e, força de vontade individual de cada aluno com o fim de alcançar metas previstas. Demonstração de segurança ao tentar e arriscar sem desistir frente a desafios cotidianos.

- Solidariedade: Revela-se pelo ato de estimular e apoiar o outro por meio do auxílio, do carinho e da atenção conferida a ele, frente às suas dificuldades e humildade em aceitar ajuda, na busca de solução dos desafios que se apresentam.

Para que se ocorra o desenvolvimento das capacidades integrais nas crianças, no que se refere á aquisição de valores, Sena (2007, p. 249) enfatiza que o jogo no contexto escolar:

[...] é visto como uma atividade que tem características próprias e cujo conteúdo pode colaborar para o pleno desenvolvimento das capacidades motrizes e expressivas da criança, além de representar um meio para se socializarem os demais conteúdos curriculares desse nível de ensino, com destaque para a formação de valores.

Sabemos que os valores são incorporados por meio de múltiplas vivências do ser humano, experenciadas em seus diversos espaços de convívio, além da escola, no seio familiar, nas igrejas, nos bairros em que vivem e, nos clubes. No processo de construção e apropriação de valores, consideramos que a escola tem uma significativa importância, por favorecer espaços e elementos como os conteúdos, as discussões e a mediação do professor, para proporcionar ações que sejam propícias à formação e internalização de valores. Segundo (GUIMARÃES, 2001, p. 19): 
Desta forma, a escola é um ambiente em que são reforçados valores correntes na sociedade convencional, mas pode e deve ser também ambiente de problematização de valores, já que na escola estão presentes, no seu dia-a-dia, vários conflitos entre valores.

\section{REVISÃO BIBLIOGRÁFICA}

O estudioso Terry Orlick, caracterizado como um dos autores mais importantes que discutem o tema relacionado aos jogos cooperativos, constatou que os jogos reproduziam estruturas da sociedade, refletindo valores sociais: "[...] é a estrutura social que determina se os membros dessa sociedade irão cooperar ou competir entre si" (ORLICK, 1989 p.19). Observou também que o individualismo é valorizado pela sociedade, trazendo consequências no sistema educacional.

Faz-se necessário, portanto, trabalhar jogos cooperativos no contexto escolar atual, pois, contribui para o desenvolvimento integral do aluno, voltados para a transformação de relações sociais entre os pares. Pois segundo Hartmann (1932 apud ORLICK, 1989, p.24): “A cooperação é a força unificadora mais positiva, que agrupa uma variedade de indivíduos com interesses separados numa unidade coletiva".

Nessa perspectiva o jogo cooperativo proporciona situações para que sejam estimuladas reflexões, as quais se tornam instrumentos para a contextualização de valores, assim consequentemente a criança terá oportunidade de internalizá-los. Para Correia (2006b e DARIDO, 2001 apud CORREIA 2007, p.2) "Nesse contexto e em busca de superar a visão excessivamente esportivizada da Educação Física e a exacerbação da competição, os Jogos Cooperativos (JC) são apresentados como uma nova e importante proposta para o cotidiano da EF escolar."

O jogo cooperativo no âmbito escolar insere-se como uma forma de experiência que segundo BROWN (1994, p.8):“... os jogos cooperativos apresentam-se como uma possibilidade diferente, uma possibilidade subversiva que nos permite a experiência de sentir que a felicidade, a alegria e o prazer podem existir sem que se precise ser derrotado o outro..."

O jogo como recurso pedagógico na Educação Física é resignificador de sentidos a partir do momento que propõe significados á diversos contextos, portanto, o jogo é capaz de trazer reflexões através da ludicidade, sendo o principal meio para provocar situações de experiências de troca de valores.

Ainda, segundo Bracht (1992, p.74. Apud Guimarães et.al. 2001). "O educador na sua prática, quer queira quer não, é um veiculador de valores. É nesse sentido que reside a ligação da forma de ensino com seu conteúdo". 
Para utilizar o jogo como conteúdo no ambiente escolar, exige do educador neste contexto, um trabalho diferenciado, pois, é de extrema importância que seu comportamento durante a aula possa garantir condições para que as crianças não percam a vontade de continuar no jogo. LIMA (1995, p. 55) destaca que:

[...] a postura do educador perante o jogo é de fundamental importância, pois a forma como concebe ou demonstra o seu interesse pelo brinquedo vai influenciar negativamente ou positivamente a criança.

O autor aponta ainda que, para utilizar o jogo como conteúdo de ensino, o educador deve continuamente buscar a apropriação de conteúdos, no qual o auxiliará durante a prática no âmbito escolar. Ou seja, "[...] a utilização do jogo como proposta de conteúdo é um processo de construção, por meio do qual o educador vai buscando competência através do aprofundamento teórico relacionado dialeticamente com a prática" (LIMA, 1995, p. 203).

\section{OBJETIVOS}

Esta pesquisa adota como objetivo geral a incorporação de valores por meio do jogo cooperativo no contexto dos anos iniciais do Ensino Fundamental. Nessa perspectiva fixam-se os seguintes objetivos específicos:

- Estimular a formação dos valores cooperação, perseverança e solidariedade.

- Proporcionar vivências significativas que venham a possibilitar mudanças qualitativas nas atitudes comportamentais dos alunos, de forma a contribuir para a minimização de conflitos relacionais;

- Intervir e propiciar situações que favoreçam a participação do aluno através de questionamentos, sugestões e apontamentos que venham a contribuir na formação de sua criticidade.

\section{METODOLOGIA}

Esta investigação de predominância qualitativa caracteriza-se como pesquisa-intervenção, a qual "[...] não visamos à mudança imediata da ação instituída, pois a mudança é conseqüência da produção de uma outra relação entre teoria e prática, assim como entre sujeito e objeto" (Aguiar e Rocha, 2003), e contará com medidas quali-quantativas por meio de instrumentos, como registros escritos, fotografias, vídeos e questionários. Aguiar (e Rocha, 1997, p.97) esclarecem que:

$\mathrm{Na}$ pesquisa-intervenção, a relação pesquisador/objeto pesquisado é dinâmica e determinará os próprios caminhos da pesquisa, sendo uma 
produção do grupo envolvido. Pesquisa é, assim, ação, construção, transformação coletiva, análise das forças sócio-históricas e políticas que atuam nas situações e das próprias implicações, inclusive dos referenciais de análise. É um modo de intervenção, na medida em que recorta o cotidiano em suas tarefas, em sua funcionalidade, em sua pragmática variáveis imprescindíveis à manutenção do campo de trabalho que se configura como eficiente e produtivo no paradigma do mundo moderno (apud Aguiar e Rocha, 2003).

Primeiramente foi enviado para o Conselho de Ética da Faculdade de Ciências e Tecnologia - UNESP Câmpus de Presidente Prudente e devidamente analisado e aprovado sob o registro: 53201 na data de 07 de Outubro de 2011.

$\mathrm{Na}$ primeira etapa será realizado um levantamento bibliográfico com autores selecionados que contemplem a temática da pesquisa e seus adendos, especificamente autores que abordem os jogos coletivos, a cooperação, a Cultura Corporal de Movimento e valores sociais relacionados.

Na segunda etapa será sistematizado um cronograma de intervenção a fim de estruturar um programa de atividades para dois semestres, período no qual a pesquisa será desenvolvida. Todavia este planejamento será passível de modificações a partir do momento em que novas problemáticas surgirem no processo de intervenção. Com o objetivo de solucioná-las, buscaremos suporte teórico de vários autores no que diz respeito a cada questão que poderá emergir.

Como terceira etapa contemplaremos as intervenções, das quais, nos utilizaremos para esta investigação. Em outras palavras, - aulas planejadas e ministradas para uma turma do terceiro ano do Ensino Fundamental de uma unidade de ensino (UE) da rede municipal de ensino do município de Presidente Prudente vinculada á Secretaria Municipal de Educação, na qual, as aulas de Educação Física serão ministradas semanalmente no período vespertino, com a duração de 50 minutos hora/aula.

A aula será estruturada em três momentos, o primeiro momento é composto pela conversa inicial, na qual os pesquisadores explicam o tema que será abordado na aula juntamente com as crianças que participam fazendo seus apontamentos relacionando a importância do tema com o seu cotidiano.

O segundo momento se dirige ás atividades coletivas que se caracterizam por ser a parte principal da aula, na qual serão tratados os jogos coletivos com o objetivo de estimular a formação de valores entre os alunos. Nessa fase os pesquisadores explicarão e acompanharão as 
atividades propostas por meio de combinados com os alunos, poderão ser modificadas a qualquer momento pelo grupo, desde que haja o consenso da maioria dos membros, seja nas regras, pontuação, divisão das equipes, limite da área de execução das atividades, líderes ou árbitros, materiais ou brinquedos a serem utilizados. Tais medidas buscam tomadas de decisão coletiva para estimular assim, a autonomia e a gestão de atitudes nos moldes objetivados nas aulas de Educação Física.

O terceiro momento é destinado para que as crianças fiquem a vontade na escolha das atividades ou brincadeiras que serão executadas, elas ficarão responsáveis pela organização das atividades e a forma como serão realizadas, suas regras e a resolução de problemas sem a intervenção dos pesquisadores que neste momento observarão a contemplação da cultura de pares.

A conversa final acontecerá logo após o terceiro momento no qual as crianças expressam o que aprenderam, avaliam a aula com seus apontamentos positivos e negativos, sugerem novas atividades a serem realizadas nas próximas intervenções. Os pesquisadores contextualizarão as problemáticas surgidas no decorrer da aula com todos os alunos, estes fazem uma auto-avaliação á respeito das atitudes comportamentais nas atividades coletivas e individuais.

Como métodos de avaliação, serão utilizados questionários que irão analisar qual a compreensão dos alunos á respeito dos valores estabelecidos. Nessa perspectiva será realizada uma auto-avaliação de suas condutas na utilização destes valores durante as atividades e em relação ás atitudes socializadas em grupo.

Nesse processo serão aplicados dois questionários com o mesmo conteúdo um no início e outro fim das intervenções. Tais instrumentos serão aplicados em sala de aula com a explicação das questões. O primeiro será empregado no terceiro bimestre do ano letivo de 2012 na fase anterior ás intervenções. O segundo questionário será aplicado no segundo bimestre do ano letivo de 2013, após o encerramento de todas as intervenções para, a partir disto comparar a evolução dos alunos no que diz respeito da formação e internalização dos valores nas atitudes comportamentais dos alunos.

\section{RESULTADOS PARCIAIS}

Foram aplicados questionários para avaliar o entendimento das crianças do terceiro ano do Ensino Fundamental a respeito de valores. Foi perguntado o que a criança entendia por 
valores, cooperação, solidariedade e perseverança para posteriormente iniciar a etapa das intervenções com os jogos cooperativos. Sobre valores, a maioria entende por educação, respeito e religiosidade, e ao serem perguntados sobre cooperação, solidariedade e perseverança a maioria não soube responder, outros apenas conjugavam em verbo, por ex: cooperar e perseverar. Os resultados parciais obtidos até o momento demonstram que é de suma importância introduzir os jogos cooperativos como recurso pedagógico, pois, é uma atividade que proporciona, ajuda mútua entre os pares, o trabalho em equipe na busca de superar desafios em comum, e a interação com o próximo. Dessa forma destacamos o jogo como um recurso essencial para a formação de valores nas crianças, pois, oferece um universo de estimulações que possibilitam evoluções significativas ao aluno dentro do contexto escolar para ampliação de habilidades motoras, capacidades de expressão e criação, entre outras.

\section{DISCUSSÕES}

Os resultados parciais sublinham a necessidade em trabalhar com jogos cooperativos na formação dos valores acima citados para que não somente seja de conhecimento das crianças o significado dos mesmos, mas, principalmente para que sejam internalizados e assim, façam parte das atitudes cotidianas das crianças.

\section{CONCLUSÃO}

A partir do exposto, consideramos esta pesquisa como de significativa relevância social. Nesse sentido acreditamos que ao oferecer ações que estimulem a formação de alguns valores através de jogos cooperativos como recurso pedagógico, aos alunos dos anos iniciais do Ensino Fundamental, poderemos proporcionar mudanças qualitativas no que diz respeito ao processo de ensino e de aprendizagem nas aulas de Educação Física.

\section{REFERÊNCIAS}

BROWN, Guillermo. - Jogos Cooperativos: teoria e prática. São Leopoldo: Sinodal, 1994. p. 105.

CORREIA, Marcos Miranda. Jogos Cooperativos e Educação Física escolar: possibilidades e desafios. Revista Digital - Buenos Aires, v. 12, n. 107, Abril de 2007.

GUIMARÃES, A. A. et. al. Educação Física Escolar: Atitudes e Valores. Motriz. Presidente Prudente, V. 7, n.1, p. 17-22, jan/jun 2001. 
LIMA, José Milton de. Educação Física no Ciclo Básico: O Jogo Como Proposta de Conteúdo. 1995. 230 f. Dissertação (Mestrado em Educação) - Faculdade de Filosofia e Ciências, Universidade Estadual Paulista - UNESP, Marília, 1995.

ORLICK, Terry. - Vencendo a competição. São Paulo: Círculo do Livro, 1989. p. 211.

ROCHA, M. L.; AGUIAR, K.F. Pesquisa-intervenção e a produção de novas análises.

Pesquisa-intervenção e a produção de novas análises. Psicol. cienc. prof. [online]. 2003, vol.23, n.4, pp. 64-73. ISSN 1414-9893.

Psicol. cienc. prof. Brasília, v.23, n.4, p.59-71 dez. 2003.

SENA, Silvio. 0 jogo como precursor de valores no contexto escolar. 2007. 242 f. Dissertação (Mestrado em Educação) - Faculdade de Ciências e Tecnologia, Universidade Estadual Paulista UNESP, Presidente Prudente, 2007. 